\title{
Insights into past tectonism from authigenic quartz
}

\section{H. Hellevang ${ }^{1 *}$, L.H. Line ${ }^{1}$, C.H. Eide ${ }^{2}$, J. Jahren ${ }^{1}$, B.G. Haile ${ }^{1}$}

Abstract

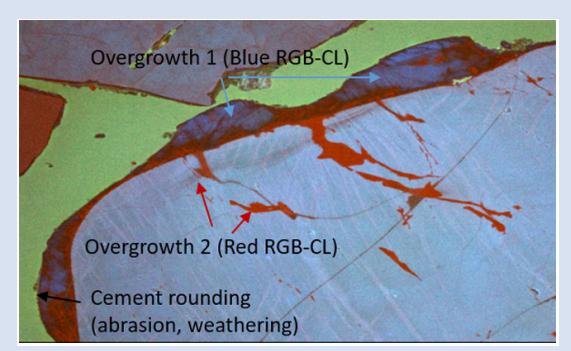

Authigenic quartz grains carry information that is diagnostic for the thermal history and thereby the burial depth and uplift of sediments. Recycled quartz grains with embayed or rounded authigenic remnants have been observed globally, but the value of these grains in unravelling past tectonism is presently underexplored. In this study, we launch a new method to demonstrate that cathodoluminescence (CL) in combination with fluid inclusion data and textural characteristics of authigenic quartz can provide important information about past tectonic activity. Vital in the method is the realisation that recycled quartz grains can be distinguished from other quartz grains by their geochemical CL fingerprint, allowing tracking of uplifted source terrains in a direction towards higher fractions of the recycled grains. Furthermore, regional mapping can reveal both intra-basinal recycling as well as recycled grains transported into the basin from external sources. The new proposed method is simple and does not require more than a standard Scanning Electron Microscope equipped with a CL detector, available at many geoscientific institutions worldwide. This innovative approach applies to a wide section of geoscientific disciplines, and complement and supplement other conventional methods used for unravelling past tectonism.

Received 6 August 2020 | Accepted 12 June 2021 | Published 15 October 2021

\section{Introduction}

Unravelling distinct fingerprints of past tectonic activity from the sedimentary record is important to understand the basin fill history. This is however not always straightforward. For example, persistent individual grains can be buried, uplifted, weathered and eroded, transported and redeposited, and even undergo several such cycles reflecting the large scale tectonic processes operating in the area over time (Fig. 1). In other words, the "sink" of one sedimentary cycle may act as the "source" for subsequent sedimentary sequences (Andersen et al., 2016). While detrital zircon dating in most cases can provide reliable source area ages, radiation damage (metamictisation) may destroy old age signatures (Andersen et al., 2016), recycling may obscure the source to sink interpretations, and zircon ages may not be unique for a given source area (Slagstad and Kirkland, 2017). Conventional source-to-sink models therefore do not apply to recycled sediments and the consequences of ignoring or misinterpreting recycled components as primary deposits may lead to incorrect provenance interpretations, inaccurate sediment budgeting, erroneous thermal histories and uplift estimates - ultimately affecting basin modelling and subsurface predictions.

During a sedimentary cycle, quartz grains can retain part of the information about their travel and the physical conditions they have been exposed to without giving information about the exact timing and duration of tectonic events. Authigenic quartz cement may form as syntaxial overgrowths on detrital quartz grains when sediments are buried to $2-3 \mathrm{~km}$ depth and temperatures reach about $70^{\circ} \mathrm{C}$ (Walderhaug, 1994). As cements completely fill irregular detrital grain surfaces, microscopic pockets of the diagenetic fluid may be trapped below the cement (Bodnar, 2003). Fluid inclusions carry a geochemical fingerprint of the temperature and pore water chemistry at the time of quartz formation, and they can be used as geothermometers and even tectonic markers recording the physical conditions at the time of quartz cementation (Walderhaug, 1994; Boullier, 1999).

Another attribute that provides additional information on the physico-chemical state of the fluid from which quartz crystallised is the cathodoluminescence (CL) spectra emitted after shooting the crystals with electrons (Götze et al., 2001; Götte and Richter, 2006). The CL spectra may also distinguish several generations of quartz cement formed during different diagenetic stages (Demars et al., 1996).

A third factor providing insight into the history of individual quartz grains is their roundness, traditionally used as an indicator for the degree of weathering and transport (Folk, 1951; Crook, 1968; Dott, 2003). Syntaxial quartz overgrowths tend to form sharp edges and straight crystal interfaces when growing unconfined, whereas chemical weathering and abrasion tend to smoothen the grain surfaces (Garzanti, 2017). Rounded authigenic cements may thus provide evidence for large scale uplift of a precursor basin and subsequent weathering, erosion and transport of its sedimentary infill.

Rounded and embayed authigenic quartz cements are found worldwide, unconstrained by time and space (Fig. 2; Johnsson et al., 1988; Rezaee and Tingate, 1997; Dott, 2003; Götte and Richter, 2006; Ulmer-Scholle et al., 2014). Despite being found in old and recycled sediments, abraded or corroded authigenic quartz cements are rarely reported.

1. Department of Geosciences, University of Oslo, P.O. BOX 1047, Blindern, 0316 Oslo, Norway

2. Department of Earth Science, University of Bergen, Allegaten 41, 5007 Bergen, Norway

Corresponding author (email: helge.hellevang@geo.uio.no) 


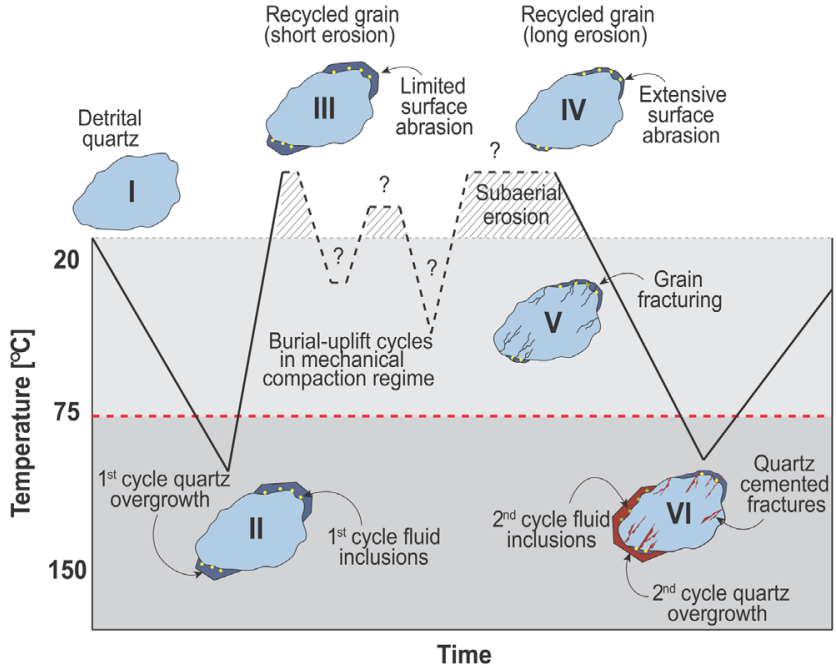

Figure 1 The temporal history of a quartz grain after deposition. Stage I to II: burial followed by diagenesis and the formation of authigenic cements as temperatures higher than $\sim 60-70{ }^{\circ} \mathrm{C}$ are reached; stage II to III: uplift; stage III to IV: weathering before transport to the final depositional setting, potentially with multiple cycles of stages I to III in between; and finally stage IV to VI: burial in a new system leading to diagenesis and again reaching the threshold temperature of $60-70{ }^{\circ} \mathrm{C}$ leading to new syntaxial authigenic quartz growth.

Attempts have previously been made to use the geochemical characteristics of clastic quartz grains as indicators of provenance and depositional history (Blatt, 1967; Augustsson and Reker, 2012; Ackerson et al., 2015), but only a couple of studies have targeted individual quartz grains as indicators of past tectonics (Vityk and Bodnar, 1995; Seyedolali et al., 1997). In this study, we launch a new method that combines fluid inclusion data with SEM-CL and that is complementary and supplementary to the standard methods that are in use to reconstruct past tectonism and provenance, and we demonstrate the kind of geochemical information individual quartz grains and quartz rich sedimentary rocks carry. We finally propose the regional mapping required to understand past tectonism of the basin and beyond. To demonstrate this, we used quartz grains from the Lower-Middle Mesozoic sedimentary succession exposed at Wilhelmøya, on the western Barents Shelf. These sediments are poorly lithified sands that have not been buried to substantial depths. Vitrinite reflectance data suggests a maximum burial temperature of $\sim 40{ }^{\circ} \mathrm{C}$ (Haile et al., 2019). As these deposits have not been exposed to depths sufficient for quartz cementation, the presence of authigenic cements clearly demonstrates that grains covered by overgrowths are allogenic and must be recycled from older units.

\section{Microscale Properties of Authigenic Quartz}

Authigenic quartz cement can be identified using a standard petrographic microscope. Quartz overgrowths $(\mathrm{QO})$ are separated from detrital quartz grains (DQ) by palaeo-rims that have accumulated dust and where fluid inclusions have formed (Fig. 3a). This observation is supported by RGB-CL intensity images highlighting the different cathodoluminescence response of authigenic cements and the detrital quartz grain (Fig. 3b). The original detrital grain constitutes the core, whereas authigenic quartz fills in fractures and covers parts of the detrital grain surface. The RGB-CL image discriminates in this case two generations of cements; an innermost dark blue cement being the oldest, and a red cement filling fractures both in the detrital quartz grain and in the blue cement. The reason for variations in the RGB colour component intensities (mainly red and blue) is not perfectly known, but is likely related to the chemicalphysical properties of the fluid from which quartz crystallises, and on the growth rate of the authigenic cement (Götte and

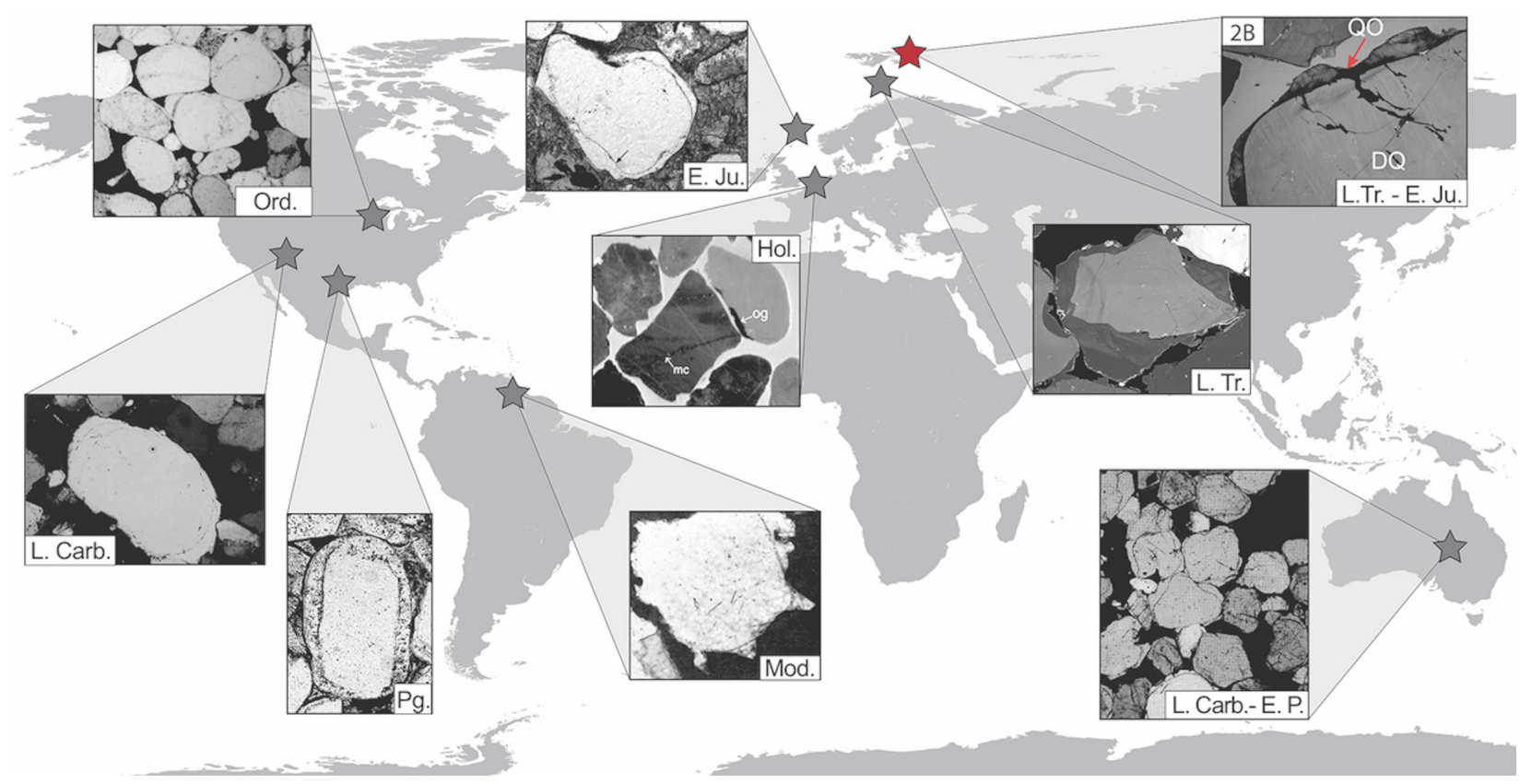

Figure 2 Rounded authigenic quartz has been reported from several stratigraphic intervals and locations worldwide. The red star indicates the position of Wilhelmøya. The figure compilation was made from Johnsson et al. (1988), Rezaee and Tingate (1997), Dott (2003), Götte and Richter (2006), and Ulmer-Scholle et al. (2014). Abbreviations: Ord. = Ordovician, L. Carb. = Late Carboniferous, E. P. = Early Permian, L. Tr. = Late Triassic, E. Ju. = Early Jurassic, Pg. = Palaeogene, Hol. = Holocene, Mod.= Modern. 

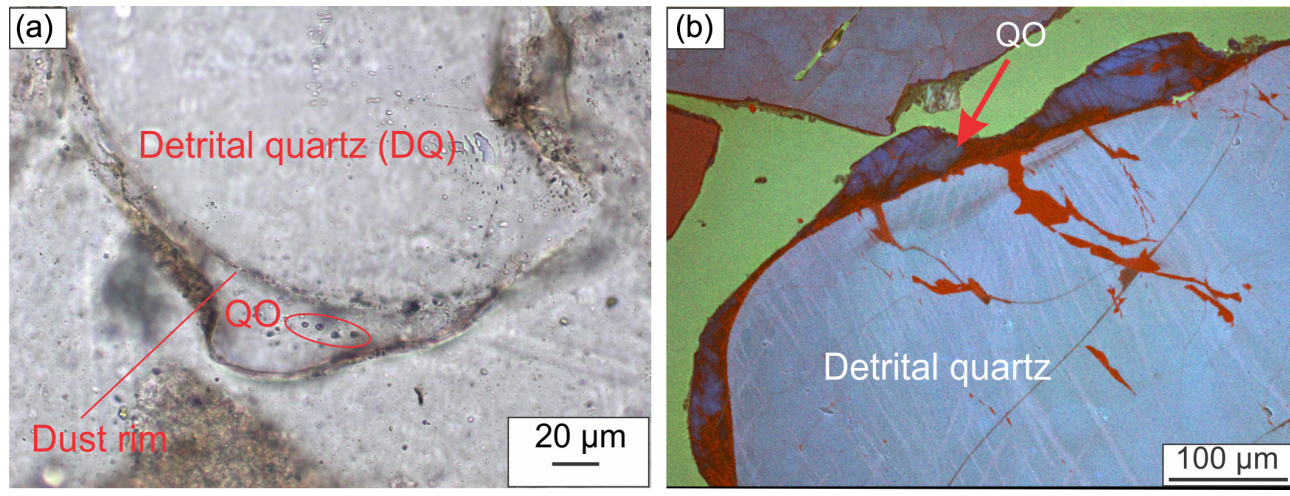

Figure $3 \mathrm{CL}$ and petrographic images showing rounded authigenic quartz overgrowths at the surface of detrital quartz grains. (a) Representative light microscope micrograph of a portion of quartz grain with dust rims and fluid inclusion assemblages (FIAs; circled) containing primary fluid inclusions. (b) RGB-CL image highlights two generations of authigenic cements. The last generation has filled in fractures in both the detrital grain and the first generation of authigenic cement.

Richter, 2006). By distinguishing detrital and authigenic quartz phases from one another, we can confirm that the investigated grain was subjected to at least one previous cycle of deep burial prior to its current compaction state. The outer edges of the quartz cement seen as dark blue in RGB-CL (Fig. 3b) are rounded to different degrees, signifying that the grain has been exposed at the Earth's surface after the authigenic cements formed at depth.

\section{Information from Single Quartz Grains}

The Wilhelmøya grains must have been buried to a depth of at least $3-4 \mathrm{~km}$ based on the highest recorded fluid inclusion temperature of $130{ }^{\circ} \mathrm{C}$ (Haile et al., 2019). Although a basin inversion of $4 \mathrm{~km}$ would certainly represent a major tectonic event, the more difficult task is to identify the palaeo-basin responsible for burying the quartz grains to these depths.

A single grain indicates sediment recycling and extent of uplift for that particular grain, but cannot say much about the locality or timing of a specific tectonic event. An in depth analysis of the quartz assemblage from a field site or drill core can however bring us closer to unravel past tectonics of a region. By analysing the CL images of a representative number of grains, normally a few hundred is sufficient (van der Plas and Tobi, 1965), one can obtain the fraction of grains that are tectonically uplifted and transported to the site. If using the RGB-CL option one can even identify authigenic grains sourced from different tectonic events, or cements formed during different stages in the same grain such as seen in Figure 3b. The RGB-CL image is like a fingerprint reflecting the different chemical and physical conditions upon the formation of the cements. One important (a) IDENTIFICATION $\longrightarrow$

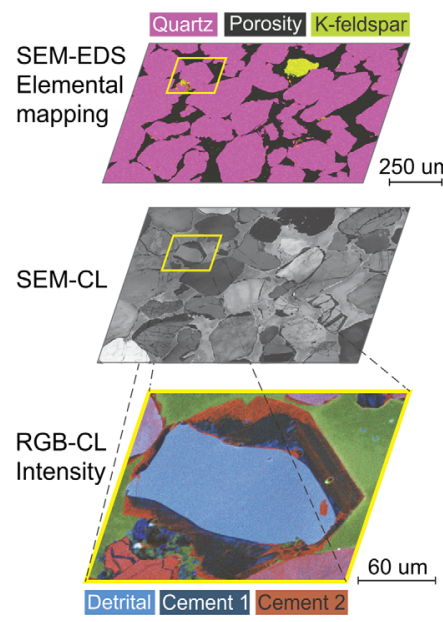

(b) QUANTIFICATION

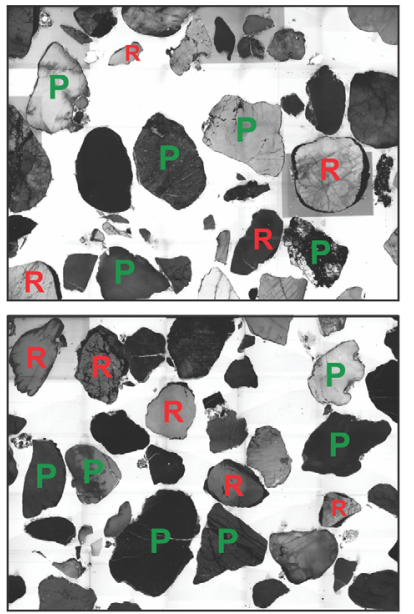

(c) REGIONAL MAPPING

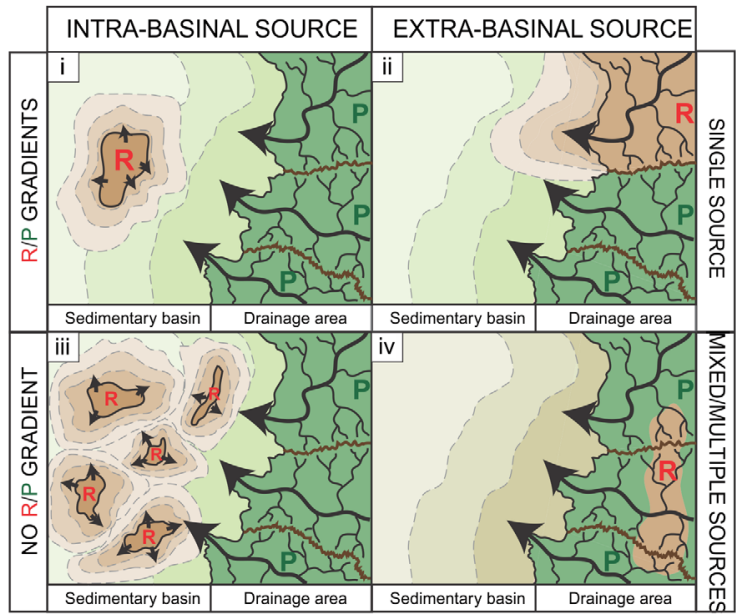

Figure 4 Suggested three step procedure to use rounded authigenic quartz cements to identify tectonic source. (a) Identification of recycled authigenic cements including collecting information about the chemical fingerprint using SEM-CL and RGB-CL. (b) Quantification of recycled (R) and other sedimentary quartz grains without authigenic fingerprints $(P)$ providing the fraction of recycled grains in the sediment. (c) Regional mapping to investigate whether the source for recycled material is intra- or extra-basinal. (i) R/P ratios are expected to increase towards a local source if recycled grains from a sole intra-basinal high are mixed with particles from an external source that dominates the input to the basin. (ii) If mixing of recycled sediment from an extra-basinal source area and other extra-basinal particles occur inside the basin, R/P fractions are expected to increase towards the drainage area where recycled units are exposed. (iii) No apparent $\mathrm{R} / \mathrm{P}$ gradients are expected if multiple intra-basinal highs exist, or (iv) if the recycled material is mixed with other sedimentary particles in the drainage system prior to entering the basin. 
factor to keep in mind when estimating the fraction of grains being recycled, is that only quartz grains must be counted and analysed. The CL images do not distinguish quartz from other minerals such as feldspars or oxides, and only quartz can carry the syntaxial overgrowths being evidence of the uplift and recycling events. Other minerals may have had nucleation and nonsyntaxial quartz cement, but this is rather an exception during sandstone diagenesis.

We propose a two step procedure for the identification and quantification of recycled grains. First quartz is separated from other minerals using SEM-EDS element mapping, before the recycled grains are identified by SEM-CL and the tectonic fingerprint is found by CL-RGB analyses together with fluid inclusion data (Fig. 4a). The second step is to separate the identified recycled grains (R) from other sedimentary quartz grains without authigenic recycling fingerprints $(\mathrm{P})$ and quantify the fraction of the former (Fig. 4b). It is important at this stage to realise that authigenic cements may be completely removed after chemical corrosion and transport, and the value of (R) must therefore be regarded a minimum estimate.

This work requires some effort, but both the SEM work and the image analyses can to a certain degree be automated thereby reducing both operator dependent factors and man hours (Sime and Ferguson, 2003; Wu et al., 2019).

\section{Integration of Recycled Quartz Grains into Regional Studies}

To identify possible tectonic source areas, it is necessary to identify and quantify recycled quartz grains in a larger region. The distribution of $\mathrm{R} / \mathrm{P}$ fractions in the basin may suggest whether the source for recycled grains is intra- or extra-basinal (Fig. 4). If the source terrain is intra-basinal and recycled grains are mixed with sediments from an external source that dominates the input to the basin, R/P gradients are expected to increase and converge towards the local source. A similar convergence of gradients is expected if mixing of recycled and sedimentary grains from different extra-basinal source areas occurs inside the basin. If, on the other hand, multiple uplifted intra-basinal sources exist, or mixing of primary and recycled particles occur in the drainage system prior to entering the sedimentary basin (Fig. 4c), no apparent R/P gradients are expected. However, it can, even in cases with multiple intra-basinal sources, be possible to identify gradients in cases with very characteristic CL-RGB signatures from specific uplift events. With this concept in mind, integrating information on the amount of recycled grains on a regional or basin scale may reveal new information on the past tectonics that no other method can provide.

\section{Conclusions}

In this paper we have launched a new methodology utilising geochemical and textural fingerprints of quartz cements to unravel past tectonics and sediment routing. The new method uses the fact that authigenic cements on single quartz grains carry chemical, textural and physical fingerprints that can provide information about depth of burial, number of former deep burial cycles and weathering and transport of the grain prior to final deposition. Integrating the analysis of single quartz grains over a region may furthermore provide the information required to understand intra- or extra-basinal past tectonism. One of the key advantages of the method is the lack of fertility biases in the quartz as it is a framework grain thus the relative proportion of the intra-basinal/extra-basinal sources can be calculated. The potential for unravelling past tectonic processes using geochemical and textural analyses of recycled grains may be attributed to polycyclic sediments worldwide. With this new application, there will be more emphasis on locating recycled quartz grains and harvest their full potential as a carrier of geological information.

\section{Acknowledgements}

We wholeheartedly thank the reviewers, Amy Gough and an anonymous reviewer for their constructive and helpful comments! The study was supported by the NRC ISBAR project (project 267689) and by VISTA (project 6270). Sample preparation and SEM analyses were performed at the University of Oslo, and we are thankful for laboratory assistance from S. Simonsen.

Editor: Gavin Foster

\section{Additional Information}

Supplementary Information accompanies this letter at https:// www.geochemicalperspectivesletters.org/article2130.

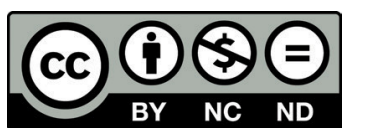

(C) 2021 The Authors. This work is distributed under the Creative Commons Attribution NonCommercial No-Derivatives 4.0 License, which permits unrestricted distribution provided the original author and source are credited. The material may not be adapted (remixed, transformed or built upon) or used for commercial purposes without written permission from the author. Additional information is available at https://www. geochemicalperspectivesletters.org/copyright-and-permissions.

Cite this letter as: Hellevang, H., Line, L.H., Eide, C.H., Jahren, J., Haile, B.G. (2021) Insights into past tectonism from authigenic quartz. Geochem. Persp. Let. 19, 27-31.

\section{References}

ACKERSON, M.R., TAILBY, N.D., WATSON, E.B. (2015) Trace elements in quartz shed light on sediment provenance. Geochemistry, Geophysics, Geosystems 16, 1894-1904.

Andersen, T., Kristoffersen, M., Elburg, M.A. (2016) How far can we trust provenance and crustal evolution from detrital zircons? A South African case study. Gondwana Research 34, 129-148.

Augustsson, C., ReKer, A. (2012) Cathodolumenescence spectra of quartz as provenance indicators revisited. Journal of Sedimentary Research 82, 559-570.

Blatt, H. (1967) Provenance determinations and recycling of sediments. Sedimentary Research 37, 1031-1044.

BoDNAR, R.J. (2003) Chapter 4. Introduction to aqueous-electrolyte fluid inclusions. In: SAMson, I., ANDERson, A., Marshall, D. (Eds.) Fluid Inclusions: Analysis and Interpretation. Mineralogical Association of Canada, Ottawa, Ont., Short Course 32, 81-99.

BOUlLIER, A.-M. (1999) Fluid inclusions - tectonic indicators. Journal of Structural Geology 21, 1229-1235.

CROOK, K.A.W. (1968) Weathering and roundness of quartz sand grains. Sedimentology 11, 171-182.

Demars, C., Pagel, M., Deloule, E., Blanc, P. (1996) Cathodoluminescence of quartz from sandtones: interpertation of the UV range by determination of trace element distributions and fluid-inclusion P-T-X properties in authigenic quartz. American Mineralogist 81, 891-901.

DoTT, R.J., JR. (2003) The importance of eolian abrasion in supermature quartz sandstones and the paradox of weathering on vegetation-free landscapes. The Journal of Geology 111, 387-405.

FOLK, R.L. (1951) Stages of textural maturity in sedimentary rocks. Journal of Sedimentary Petrology 21, 127-130.

GARZANTI, E. (2017) The maturity myth in sedimentology and provenance analysis. Journal of Sedimentary Research 87, 353-365. 
GötTe, T., RichteR, D.K. (2006) Cathodoluminescence characterization of quartz particles in mature arenites. Sedimentology 53, 1347-1359.

Götze, J., Plötze, M., Habermann, D. (2001) Origin, spectral characteristics and practical applications of the cathodoluminescence (CL) of quartz - a review. Mineralogy and Petrology 71, 225-250.

Haile, B.G., Czarniecka, U., XI, K., Smyrak-Sikora, A., Jahren, J., BraAthen, A Hellevang, H. (2019) Hydrothermally induced diagenesis: Evidence from shallow marine-deltaic sediments, Wilhelmøya, Svalbard. Geoscience Frontiers 10, 629-649.

Johnsson, M.J., Stallard, R.F., Meade, R.H. (1988) First-cycle quartz arenites in the Orinoco river basin, Venezuela and Colombia. The Journal of Geology 96, 263-277.

RezAEE, M.R., Tingate, P.R. (1997) Origin of quartz cement in the Tirrawarra sandstone, southern Cooper Basin, South Australia. Sedimentary Research 67, 168-177.

Seyedolali, A., Krinsley, D.H., Boggs, S., JR., O’Hara, P.F., DypviK, H., Goles, G.G. (1997) Provenance interpretation of quartz by scanning electron microscopy - cathodoluminescence fabric analysis. Geology 25, 787-790.

SimE, L.C., FERGUSON, R.I. (2003) Information on grain sizes in gravel-bed rivers by automated image analysis. Journal of Sedimentary Research 73, 630-636.

Slagstad, T., KIRKLAND, C.L. (2017) The use of detrital zircon data in terrane analysis: A nonunique answer to provenance and tectonostratigraphic position in the Scandinavian Caledonides. Lithosphere 9, 1002-1011.

Ulmer-Scholle, D.S., Scholle, P.A., Schieber, J., Raine, R.J. (2014) A color guide to the petrography of sandstones, siltstones, shales and associated rocks. American Association of Petroleum Geologists, Tulsa, OK, Memoir 109.

VAN DER PLAS, L., TOBI, A.C. (1965) A chart for judging the reliability of point counting results. American Journal of Science 263, 87-90.

VITYK, M.O., BODNAR, R.J. (1995) Textural evolution of synthetic fluid inclusions in quartz during reequilibration, with applications to tectonic reconstruction. Contributions to Mineralogy and Petrology 121, 309-323.

WaLDERHAUG, O. (1994) Precipitation rates for quartz cement in sandstones determined by fluid-inclusion microthermometry and temperature-history modelling. Sedimentary Research 64, 324-333.

Wu, Y., Misra, S., Sondergeld, C., Curtin, M., Jernigen, J. (2019) Machine learning for locating organic matter and pores in scanning electron microscopy images of organic-rich shales. Fuel 253, 662-676. 